\title{
Cytokines and the Role of Immunomodulation in Heart Failure of Different Etiologies
}

\author{
Dinko Anzulović-Miroševići, ${ }^{1 *}$, Martina Zaninotto², Monica Maria Mion², Mario Plebani², \\ Sergio Dalla-Volta ${ }^{1}$ \\ ${ }^{1}$ Department of Cardiology, University of Padua Medical School, Padua, Italy \\ ${ }^{2}$ Department of Laboratory Medicine, University of Padua Medical School, Padua, Italy \\ ${ }^{3}$ Padova Medica Cardiology Division, Padua, Italy
}

\begin{abstract}
*Corresponding Author: Dinko Anzulović-Mirošević, Department of Cardiology, University of Padua Medical School, Padua, Italy. Email: anzumd@yahoo.com
\end{abstract}

\begin{abstract}
For some time now, scholars have been describing a number of activation patterns of the immune response in the acute phase of myocardial infarction. What has been less studied are the modifications concerning both chronic ischemic patients with the chronic ischemic cardiomyopathy and patients with heart failure of any aetiology. It would, therefore, be of utmost importance to analyse and understand the impact of the factors regulating the immune response during longer intervals of time, starting with the acute phase. Since the therapeutical approach has, until now, failed to produce a positive result - as has been the case with tumor necrosis factor $\alpha(T N F-\alpha)$ inhibitors - we believed that a pharmaceutical approach, involving a modulation of other immune response pathways could have a higher probability of producing more successful results. For these reasons we studied the following group of patients: 44 subjects (male to female ratio 6,33), ranging from 40 to 80 years, mean age 61, SD 9,8, with left ventricular dysfunction caused by different cardiac disorders, and a group of 29 healthy individuals as a control group. The levels of a number of biochemical markers (tumor necrosis factor alpha, TNF- $\alpha$; interferon $\gamma$, IFN- $\gamma$; interleukin-6, IL-6; interleukin-10, IL-10) were analysed and compared in the patient and the control group. Statistically significant differences in the levels of IFN- $\gamma$ and IL-6 between the chronic patients and the healthy controls were observed (IFN- $\gamma$ 180, $20 \mathrm{pg} / \mathrm{ml}$, SD 108, $13 \mathrm{vs} .223,74 \mathrm{pg} / \mathrm{ml}, \mathrm{SD}$ 69, 91, p=0,019; IL-6 3, $69 \mathrm{pg} / \mathrm{ml}, \mathrm{SD}$ 2, 42 vs. 1, $49 \mathrm{pg} / \mathrm{ml}, \mathrm{SD} 0,44, \mathrm{p}<0,0001)$.
\end{abstract}

Conclusion:The most striking difference between the patients and the healthy controls was that the level of IFN- $\gamma$ was lower among the patients. As expected, IL-6 value was higher in the patients, while no significant differences were observed for the levels of TNF- $\alpha$ and IL-10. Based on these data, we can speculate that the modulation of the interferon molecules family could have a useful clinical effect among heart failure population.

Keywords: cytokines, interferon $\gamma$, heart failure, left ventricular dysfunction.

Abbreviations: 2D-two dimensional, AMI-acute myocardial infarction, ANOVA-Analysis of Variance, BTbody temperature, CHF-chronic heart failure, CMP-cardiomyopathy, ECG-electrocardiogram, EDV-end diastolic volume, EF- ejection fraction, ESV-end systolic volume, LV-left ventricle, NYHA-New York Heart Association, P-pressure, WHO-World Health Organization

\section{INTRODUCTION}

Over the years, the occurrence of inflammation in chronic heart failure (CHF) and acute myocardial infarction (AMI) has been widely described. [1-15]. Consistent data indicate fluctuations in cytokine levels in patients with a reduced left ventricular function. However, the role of the inflammatory response in the evolution of heart failure has not been defined yet. In order to fill this critical gap, we investigated the circulating levels of several cytokines in patients with left ventricular dysfunction.

In the absence of a univocal definition of heart failure and its severity, we decided to limit our study to patients with a clinically-relevant left ventricular systolic dysfunction, assessed according to standard echocardiographic parameters. Moreover, in order to clarify whether shifts in cytokines profile were also present in the early stages of the left ventricular dysfunction, we included in our study also 
patients with a left ventricular dysfunction, caused by an acute myocardial infarction (AMI). We assumed that these patients had normal levels of circulating cytokines before the infarction. However, it is possible that some shifts are also induced by inflammatory processes of an acute myocardial infarction and not merely by left ventricular dysfunction.

\section{Materials And Methods}

For this study we recruited 44 patients, admitted to our department (male to female ratio 6,33), ranging from 40 to 80 years, mean age $61, \mathrm{SD}$ 9,8 , suffering from different cardiac diseases. The inclusion criteria were the presence of dilated cardiomyopathy (according to the WHO criteria), valvular heart disease and postischemic cardiomyopathy (previous MI older than 6 months). We also included in the study a group of patients with acute myocardial infarction (AMI), who were hospitalized at the same time.

As assessed by echocardiography, systolic LV function was impaired in all the included patients even when excluding heart diseases beyond those matching the inclusion conditions. All patients, except for those with AMI, were admitted on the grounds of unsatisfactory cardiac conditions (moderate dyspnoea on exertion and reduced effort tolerability). The patients were compared to 29 healthy subjects (anamnestically no signs of diseases, negative physical examination and ECG), non agematched (13 males and 16 females, ranging between 20 and 63 years with a mean age of 30,2 years, SD 13.67). The Ethical Committee of the University of Padua approved the study; an informed consent was obtained from each patient.

All patients were submitted to a detailed anamnesis, physical examination, ECG, and a routine laboratory analysis. The cardiac functional impairment was graded according to the NYHA class; the non-invasive hemodynamic evaluation was obtained by the standard 2D echocardiogram. The left ventricular systolic dysfunction was diagnosed on the basis of an ejection fraction below 55\%, although $90 \%$ of patients had values below $45 \%$. Patients with a relevant liver or kidney dysfunction, or with other major acute pathologies, such as sepsis, end stage tumours etc. were not included in the study. None of the patients had fever (body temperature $>37^{\circ} \mathrm{C}$ ) or ARC Journal of Cardiology diarrhea during sampling. At the moment of hospitalization, all patients with a chronic left ventricular dysfunction were receiving oral therapy, consisting of ACE inhibitors and diuretics. Patients with AMI did not receive any intravenous therapy during sampling.

For the biochemical analysis, a sample of $24 \mathrm{ml}$ of blood was collected in the morning (7.30$8.30 \mathrm{AM}$ ), while patients were still lying in their beds, using $21 \mathrm{G}$ butterfly needles and vacutainer system containers. The sampling was performed on all the patients within 48 hours of their admission, except in the case of patients suffering under AMI, who had their samples taken 4 to 7 days after an acute episode. The samples were kept at $4^{\circ} \mathrm{C}$ during the transport to the laboratory, where they were processed. The time between sampling and processing was between 15 to 45 minutes. With an appropriate calibration of instruments, biochemical analyses were performed at the Department of Laboratory Medicine of the University Hospital of Padua.

To determine circulating cytokine levels, blood samples were centrifuged at a $3500 \mathrm{rpm}$ for 10 minutes. Samples of plasma were stored at $80^{\circ} \mathrm{C}$, and analyzed within 6 months. Samples were then diluted in physiological solution, and levels of TNF- $\alpha$, IFN- $\gamma$, IL- 6 and IL-10 were assessed by means of commercially-available ELISA kits (eBioscience, distributed by Prodotti Gianni, Milan, Italy), according to the manufacturer's instructions. Optical densities were measured using an ELISA plate-reader (Spectra I Tecan, Gratz, AU) at $405 \mathrm{~nm}$. The concentration of cytokines in the samples was calculated according to a standard curve performed for each determination and expressed as $\mathrm{pg} / \mathrm{ml}$. ELISA assays were doubly performed. The sensitivity of the assays ranged from 15 $\mathrm{pg} / \mathrm{ml}$ to $5 \mathrm{pg} / \mathrm{ml}$. The data was elaborated with statistical analyses (descriptive statistics, MannWhitney test, Pearson linear coefficient of correlation, linear regression and ANOVA). $\mathrm{P}<0.05$ was considered statistically significant.

\section{RESUltS}

The results of the analysis are summarized in Table 1, 2. (cytokines levels) and Table 3. (hemodynamic and clinical data). Among the circulating cytokines tested in this study, we found no statistical difference in the levels of TNF- $\alpha$ and IL-10 between the patient population and the control subjects (tab. 1). Simultaneously, though, levels of circulating IL6 were significantly increased in the patient

Page $\mid 6$ 
population compared with the healthy subjects $(\mathrm{P}<0.0001)$. Also, surprisingly, levels of circulating IFN- $\gamma$ were higher in the healthy subjects than in the patients (tab. 2, fig. 1).

Table1. Mann Whitney test, cytokines, chronic patients vs. controls

\begin{tabular}{|l|l|l|l|}
\hline \multicolumn{1}{|c|}{ Parameter } & \multicolumn{1}{c|}{ Mean patients $(\mathbf{p g} / \mathbf{m l})$} & \multicolumn{1}{c|}{ Mean controls $\mathbf{( p g} / \mathbf{m l})$} & \multicolumn{1}{c|}{ p value } \\
\hline TNF- $\alpha$ & 21,08 & 21,19 & $\mathrm{p}=0,9 \mathrm{~ns}$ \\
\hline IFN- $\gamma$ & 180,20 & 223,74 & $\mathrm{P}=0,019$ \\
\hline IL -6 & 3,69 & 1,49 & $\mathrm{p}<0,0001$ \\
\hline IL-10 & 17,44 & 17,28 & $\mathrm{p}=0,71 \mathrm{~ns}$ \\
\hline
\end{tabular}

Table2. Mann Whitney test, IFN- $\gamma$ levels, patients divided by pathology vs. controls

\begin{tabular}{|l|l|l|l|l|l|l|l|}
\hline & Valid N & $\begin{array}{l}\text { Mean } \\
(\mathrm{pg} / \mathrm{ml})\end{array}$ & $\begin{array}{l}\text { Median } \\
(\mathrm{pg} / \mathrm{ml})\end{array}$ & $\begin{array}{l}\text { Minimum } \\
(\mathrm{pg} / \mathrm{ml})\end{array}$ & $\begin{array}{l}\text { Maximum } \\
(\mathrm{pg} / \mathrm{ml})\end{array}$ & $\begin{array}{l}\text { Std.Dev. } \\
(\mathrm{pg} / \mathrm{ml})\end{array}$ & $\begin{array}{l}\mathrm{p} \\
\text { vs.controls }\end{array}$ \\
\hline IFN- $\gamma$ all chronic patients & 37 & 180,20 & 156,90 & 16,89 & 392,05 & 108,13 & $\mathrm{P}=0,019$ \\
\hline IFN- $\gamma$ non ischemic CMP & 18 & 179,88 & 165,09 & 54,90 & 377,20 & 96,13 & $\mathrm{P}=0,049$ \\
\hline IFN- $\gamma$ ischemic CMP & 19 & 180,49 & 143,22 & 16,89 & 392,05 & 121,06 & $\mathrm{P}=0,04$ \\
\hline IFN- $\gamma$ AMI patients & 7 & 161,63 & 101,60 & 59,05 & 376,54 & 125,67 & $\mathrm{P}=0,055$ \\
\hline IFN- $\gamma$ controls & 29 & 223,74 & 244,70 & 73,82 & 336,88 & 69,91 & \\
\hline
\end{tabular}

Table3. Hemodynamic and clinical data for patients

\begin{tabular}{|l|l|l|l|l|l|l|l|}
\hline Parameter & & $\mathrm{N}$ & Mean & Median & Minimum & Maximum & Std. Deviation \\
\hline NYHA class & Non Ischemic CMP & 18 & 2,72 & 3 & 1 & 4 & 1,01 \\
\hline & Ischemic CMP & 19 & 3,00 & 3 & 1 & 4 & 0,88 \\
\hline & AMI* & 7 & 2,42 & 2 & 1 & 4 & 0,97 \\
\hline & TOTAL & 44 & 2,79 & 3 & 1 & 4 & 0,95 \\
\hline EF $(\%)$ & Non Ischemic CMP & 18 & 29,61 & 29,50 & 20,00 & 41,00 & 5,60 \\
\hline & Ischemic CMP & 19 & 31,15 & 30,00 & 22,00 & 48,00 & 6,76 \\
\hline & AMI & 7 & 40,57 & 42,00 & 30,00 & 52,00 & 8,32 \\
\hline & TOTAL & 44 & 32,02 & 30,50 & 20,00 & 52,00 & 7,47 \\
\hline EDV $(\mathrm{ml} / \mathrm{m} 2)$ & Non Ischemic CMP & 18 & 147,22 & 143,00 & 58,00 & 259,00 & 45,73 \\
\hline & Ischemic CMP & 19 & 138,21 & 132,00 & 92,00 & 201,00 & 28,22 \\
\hline & AMI & 7 & 85,85 & 83,00 & 56,00 & 110,00 & 19,48 \\
\hline & TOTAL & 44 & 133,56 & 131,50 & 56,00 & 259,00 & 40,88 \\
\hline AGE & Non Ischemic CMP & 18 & 56,72 & 60,50 & 39,00 & 71,00 & 9,95 \\
\hline & Ischemic CMP & 19 & 64,00 & 66,00 & 49,00 & 80,00 & 8,15 \\
\hline & AMI & 7 & 63,2 & 61,00 & 43,00 & 78,00 & 11,16 \\
\hline & TOTAL & 44 & 60,90 & 61,00 & 39,00 & 80,00 & 9,84 \\
\hline
\end{tabular}

* NYHA class for AMI patients is evaluated in the day of sampling

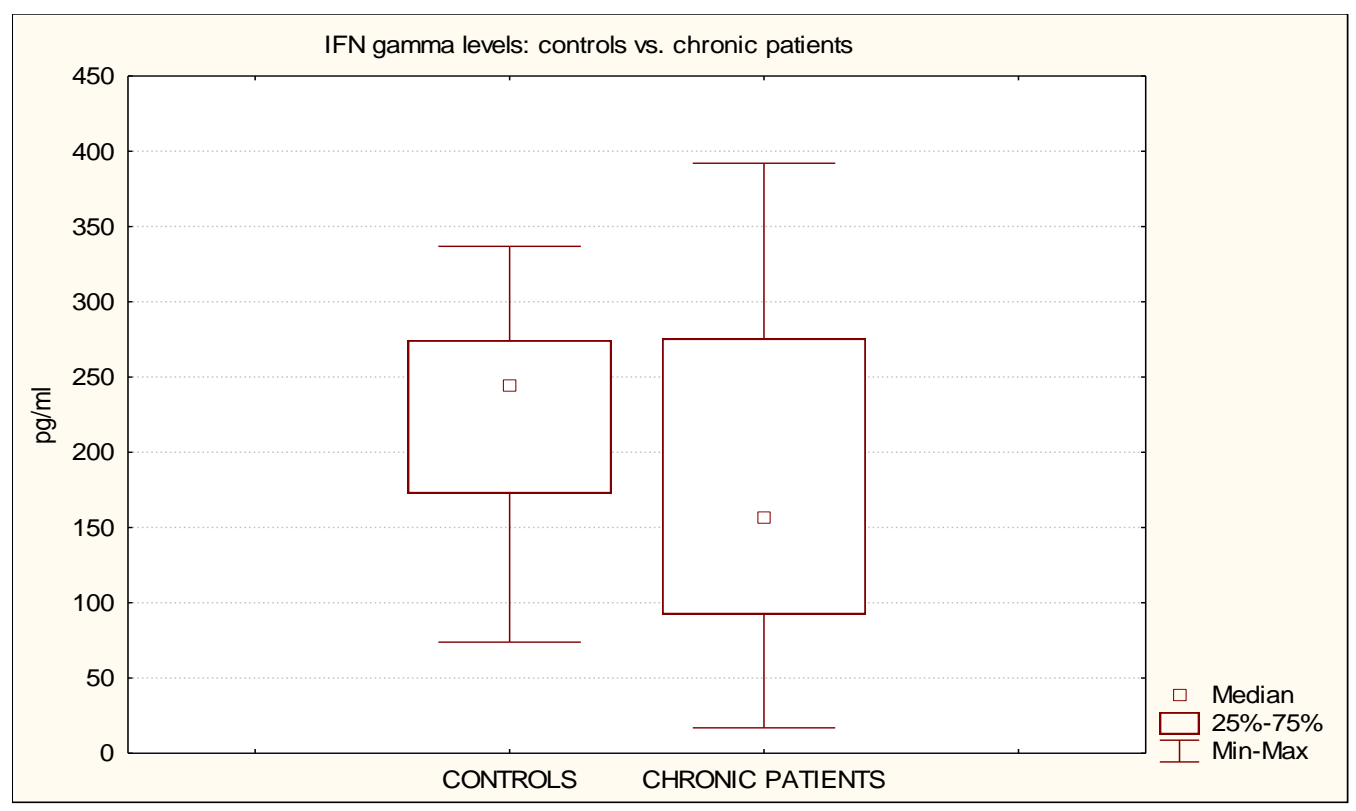

Figure1. IFN- $\gamma$ levels in controls vs. chronic patients (MW test, $p=0,019)$ 
ANOVA performed on all the chronic patients showed no significant differences in the NYHA class and the echocardiographic parameters. Analysing all chronic patients together, a faint but fairly significant positive correlation $(\mathrm{r}=0,33, \mathrm{p}=0,045)$ between IL- 6 and the NYHA class could be observed. At the same time, levels of other analysed cytokines did not correlate significantly with the NYHA class, age, LVEDV or LVEF.

\section{DISCUSSION}

We observed that the levels of IFN- $\gamma$ were higher in the control subjects than in all the patients. At the best of our knowledge, this is the first time that the analysed cytokine is higher with healthy subjects than with patients with heart failure [16]. The meaning and the impact of this finding must be studied further.

Considering the multiplicity of the modulatory effects of IFN- $\gamma$, an increased immunological activity during heart failure could therefore possibly result from reduced inhibition, usually performed by this particular cytokine rather than only by the augmented stimulating cytokines. Moreover, a similar behaviour of this parameter in cases of left ventricular dysfunction, caused by AMI, makes us believe that this type of activation of interferon gamma response in such patients happens at a very early stage. Since the progression of the left ventricular dysfunction and heart failure are believed to be partly due to inflammation, such activation of interferon gamma response could be one of the mechanisms fuelling the process. If this causation is correct, it would be crucial to obtain more data since it might lead to a possible therapeutical target.

This conclusion seems to be corroborated by some animal studies. Within these, the IFN- $\gamma$ knockout mice developed more ventricular hypertrophy and fibrosis in an experimental model of hypertensive cardiopathy [17] and a moresevere ventricular dysfunction in a different experimental model of autoimmune myocarditis [18].

Even if the administration of exogenous IFN- $\gamma$ at therapeutical level for several pathologies [19] has shown some degree of deterioration of heart failure, we believe it to be caused by very high levels, far above the physiological ones. This seems also to be shown by some animal studies [20, 21]. Although administration of lower doses could be beneficial, it needs to be clinically tested before being accepted as a therapeutical possibility. Considering the observed variability of levels of IFN- $\gamma$ in heart failure patients, it is possible to make a hypotheses that administration of IFN- $\gamma$ could be beneficial only with patients with lower than normal levels of this molecule, thus demanding an individualized therapy.

In a very specific setting of diastolic heart failure, caused by hypertrophic cardiopathy in Friedreich's ataxia, there is a report of a single case of therapeutical benefit of IFN- $\gamma$ therapy, used as enhancer of frataxine expression. Regrettably, the meaning of this finding is limited probably only to frataxine-deficient individuals [22].

The immunomodulating therapy of heart failure has unfortunately been halted due to the failure of anti-TNF- $\alpha$ to show any clinical benefits [23]. Levels of TNF- $\alpha$ were slightly higher in the patient population than in the controls, lacking any statistical significance. In contrast, other authors were able to demonstrate significant increases of TNF- $\alpha$ levels in patients in larger series, but with large internal variability of the data [24, 25].

Considering the available data, TNF- $\alpha$ might not be an appropriate therapy target for heart failure. The levels of IL-10 were slightly higher in the patient population than in the controls, lacking any statistical significance. This molecule might, therefore, not play a significant role in the progression of left ventricular dysfunction and heart failure. As expected, IL-6 has shown significantly higher levels in the patient population than in the control group.

\section{Conclusions}

The most striking difference between the patients and the healthy was a lower level of IFN- $\gamma$ among the patients in comparison to the control group. IL-6 was higher as expected in the patients, while no significant differences were observed for the levels of TNF- $\alpha$ and IL10. Judging from this data, we can speculate that the modulation of the interferon molecules family could have a useful clinical effect among heart failure population. It is possible that the administration of the IFN- $\gamma$ to the patients with lower levels of this molecule in doses sufficient to reach the physiological levels could achieve this modulation, thus reducing the progression of left ventricular dysfunction and heart failure. Further clinical research is necessary to test this hypothesis. 


\section{ACKNOWLEDGMENTS}

The authors wish to thank Luisa Barzon MD, Ignazio Castagliuolo MD, Paola Brun $\mathrm{PhD}$, Giorgio Palù MD for the part of biochemical analyses; Meri Mirošević Anzulović MS from University of Split, Croatia, for statistical analysis and Dr. Sunčica Klaas from PotsdamUniversity, Potsdam, Germany for text reviewing.

\section{REFERENCES}

[1] Pye M.; Rae A.P.; Cobbe SM. Study of Serum C-reactive Protein Concentration in Cardiac Failure. Br. Heart J. 1990, 63(4), 228-30.

[2] Packer M. The Neurohormonal Hypoteses: A Theory to Explain the Mechanism of Disease Progression in Heart Failure. JACC 1992, 20, 248-254.

[3] Mann DL. Mechanisms and Models in Heart Failure. Circulation 1999, 100, 999-1008.

[4] Mc Donagh T. Biochemical Detection of LeftVentricular Dysfunction. Lancet 1998, 351, 913.

[5] Steele I.C.; Nugent A.M.; Maguire S.; Hoper M.; Campbell G.; Halliday M.I.; Nicholls D.P. Cytokine Profile in Chronic Cardiac Failure. Eur. J. Clin. Invest. 1996, 26(11), 1018-22.

[6] Anker S.D.; Egerer K.R.; Volk H.D.; Kox W.J.; Poole-Wilson PA.; Coats A.J. Elevated Soluble CD14 Receptors and Altered Cytokines in Chronic Heart Failure. J.Am.Coll.Cardiology 1997, 79(10), 1426-30.

[7] Sato Y.; Takatsu Y.; Kataoka K.; Yamada T.; Taniguchi R.; Sasayama S.; Matsumori A. Serial Circulating Concentrations of CRP, IL4 and IL6 in Patients with Acute Left Heart Decompensation. Clin. Card. 1999, 22, 811813.

[8] Kaneko K.; Kanda T.; Yamauchi Y.; Hasegawa A.; Iwasaki T.; Arai M.; Suzuki T.; Kobayashi I.; C-Reactive Protein In Dilated Cardiomyopathy. Cardiology 1999, 91(4), 2159.

[9] Anzulović-Mirošević D.; Erente G.; Zaninotto M; Plebani M.; Rozga A.; Dalla-Volta S. Neurohormonal Changes, Inflammation, Cellular Death and Left Ventricular Function in Valvular Heart Disease. In Kimchy A: New Trends In Research, Diagnosis And Treatment In Heart Failure. ISBN 88-323-2713-9. A.Monduzzi Publ., Bologna 2002, 457-466.

[10] Kinlay S.;Selwyn A.P.; Delagrange D.; Creager M.A.; Libby P.; Ganz P.; Inflammation, the Endothelium, and the Acute Coronary Syndromes." J. Cardiovasc. Pharm. 1998, 32 (Suppl. 3), S62-66.

[11] Dalla Volta S.; Anzulović-Mirošević D.; Erente G. The Endothelial Dysfunction in Heart
Failure: The Biological Basis for Treatment. Abstracts Of 7th World Congress On Heart Failure- Mechanisms And Management. Vancouver BC, July 9-12, 2000. J. Of Heart Failure 2000, 6, 83

[12] Anzulović-Mirošević D.; Razzolini R.; Zaninotto M.; Mion M.M.; Plebani M.; Rozga A.; Dalla-Volta S.; The C-reactive protein levels in left ventricular dysfunction of different etiology: Inflammation and AllergyDrug Targets 2009;8, 247-251

[13] Mollnes T.E.; Tambs K.E.; Myreng Y. Engebretsen L.F. Acute Phase Reactants and Complement Activation in Patients with Acute Myocardial Infarction. Complement 1988, 5(1), 33-9.

[14] Niebauer J.;Volk H.; Kemp M.; Dominguez M.; Schumann R.R.; Rauchhaus M.; PooleWilson P.A.; Coats A.J.; Anker S.D.; Endotoxin and Immune Activation in Chronic Heart Failure: A Prospective Cohort Study. Lancet 1999, 353, $1838-42$.

[15] Anzulović-Mirošević D.; Barzon L.; Castagliuolo I.; Brun P.; Palu G.; Zaninotto M; Mion M.M.; Plebani M.; Dalla-Volta S.; LPS In Patients With Left Ventricular Dysfunction Of Ischemic And Non-Ischemic Origin; Cardiovasc Hematol Disord Drug Targets. 2011; Volume 11 Issue 2, 74-78.

[16] Scott P. Levick S.P, Paul H. Goldspink P.H.; could interferon-gamma be a therapeutic target for treating heart failure? Heart Fail Rev 2014; 19:227-236

[17] Garcia AG, Wilson RM, Heo J, Murthy NR, Baid S, Ouchi N, Sam F. Interferon- $\gamma$ ablation exacerbates myocardial hypertrophy in diastolic heart failure. Am J Physiol Heart Circ Physiol. 2012 Sep 1; 303(5):H587-96.

[18] Afanasyeva M, Georgakopoulos D, Belardi DF, Bedja D, Fairweather D, Wang Y, Kaya Z, Gabrielson KL, Rodriguez ER, Caturegli P, Kass DA, Rose NR. Impaired up-regulation of $\mathrm{CD} 25$ on CD4+ $\mathrm{T}$ cells in IFN-gamma knockout mice is associated with progression of myocarditis to heart failure. Proc Natl Acad Sci U S A. 2005 Jan 4; 102(1):180-5.

[19] Feenstra J, Grobbee DE, Remme WJ, Stricker BH. Drug-induced heart failure. J Am Coll Cardiol. 1999 Apr; 33(5):1152-62.

[20] Reifenberg K, Lehr HA, Torzewski M, Steige G, Wiese E, Küpper I, Becker C, Ott S, Nusser $\mathrm{P}$, Yamamura K, Rechtsteiner G,Warger T, Pautz A, Kleinert H, Schmidt A, Pieske B, Wenzel P, Münzel T, Löhler J.; Interferongamma induces chronic active myocarditis and cardiomyopathy in transgenic mice. Am J Pathol. 2007 Aug; 171(2):463-72.

[21] Torzewski M, Wenzel P, Kleinert H, Becker C, El-Masri J, Wiese E, Brandt M, Pautz A, Twardowski L, Schmitt E, Münzel T, 
Reifenberg K. Chronic inflammatory cardiomyopathy of interferon $\gamma$-over expressing transgenic mice is mediated by tumor necrosis factor- $\alpha$.; Am J Pathol. 2012 Jan; 180(1):73-81.

[22] Wyller VB, Jacobsen K, Dahl MB, Nilsen H, Proske S, Horter T, Brun H. Interferon gamma may improve cardiac function in Friedreich's ataxia cardiomyopathy. Int J Cardiol. 2016 Oct $15 ; 221: 376-8$

[23] Chung E.S.; Packer M.; Lo K.H; Fasanmade A.A.; Willerson J.T.; Randomized, DoubleBlind, Placebo-Controlled, Pilot Trial of Infliximab, a Chimeric Monoclonal Antibody to Tumor Necrosis Factor, in Patients with
Moderate-to-Severe Heart Failure. Results of the Anti-TNF Therapy against Congestive Heart Failure (ATTACH) Trial. Circulation. 2003, 107, 3133-3140.

[24] Levine B, Kalman J, Mayer L, Fillit HM, Packer M. Elevated circulating levels of tumor necrosis factor in severe chronic heart failure. N Engl J Med 1990; 323:236-41.

[25] Testa M, Yeh M, Lee P, et al. Circulating levels of cytokines and their endogenous modulators in patients with mild to severe congestive heart failure due to coronary artery disease or hypertension. J AmColl Cardiol 1996; 28:964 71.

Citation: Dinko Anzulović-Mirošević, Martina Zaninotto, Monica Maria Mion, Mario Plebani, Sergio DallaVolta. Cytokines and the Role of Immunomodulation in Heart Failure of Different Etiologies, ARC Journal of Cardiology. 2018; 4(2): 5-10. doi: dx.doi.org/ 10.20431/2455-5991.0402002.

Copyright: (C) 2018 Authors. This is an open-access article distributed under the terms of the Creative Commons Attribution License, which permits unrestricted use, distribution, and reproduction in any medium, provided the original author and source are credited. 